\title{
Improved microstructure and free efflorescence geopolymer binders
}

\author{
Chantale Njiomou Djangang $^{1}$ (D) Jean Aime Mbey ${ }^{1}$. Cyprien Joel Ekani ${ }^{1} \cdot$ Severin Tabou Tiam ${ }^{1} \cdot$ Philippe Blanchart $^{2}$. \\ Daniel Njopwouo ${ }^{1}$
}

Received: 27 June 2020 / Accepted: 25 November 2020 / Published online: 7 December 2020

(c) Springer Nature Switzerland AG 2020

\begin{abstract}
Two geopolymer binders that did not exhibit efflorescence, even after partial immersion in water for more than 45 days were successfully obtained from a mixture of aluminosilicates (kaolin and bauxite) with talc, and a mixture solution of potassium hydroxide and potassium silicate. Leaching tests in water were not able to quantify the occurrence of free alkali metals in the surface. The identification of structural characteristics was by solid-state nuclear magnetic resonance spectroscopy, $\mathrm{X}$-ray diffraction, fourier transform infrared spectroscopy and scanning electron microscopy. They showed the occurrence of a structural arrangement with $\mathrm{K}_{2} \mathrm{O}-\mathrm{MgO}-\mathrm{Al}_{2} \mathrm{O}_{3}-\mathrm{SiO}_{2}$ where $\mathrm{K}_{2} \mathrm{O}$ and $\mathrm{MgO}$ are additional components from usual geopolymers. The improved structural characteristics limit drastically the leakage of alkali metals and their diffusion toward the surface. In comparison to usual geopolymers-based solely on aluminosilicates, the linear shrinkage is reduced, and the mechanical strength is similar. The results turned the use of talc and potassium hydroxide and silicate as a promising way of achieving an improved durability that is required for ensuring the properties in use of geopolymers.
\end{abstract}

Keywords Geopolymer · Efflorescence ·Talc $\cdot$ K-activation solution

\section{Introduction}

Geopolymer has emerged as an innovative technology for sustainable building and civil engineering; pioneered by Joseph Davidovits [1, 2]. It is the product of "geopolymerisation" that is a reaction at room temperature or slight high temperature between aluminosilicate powder as precursors and a high alkaline solution. The powder of precursor provides silicon ( $\mathrm{Si}$ ) and aluminum (Al) that dissolve into the alkaline activator solution and then polymerize to form a polymeric $\mathrm{Si}-\mathrm{O}-\mathrm{Al}-\mathrm{O}$ framework that forms the binder. As well as Portland binder's, geopolymer materials are attractive because of their excellent mechanical properties, durability and thermal stability. In addition, owing to their low calcium content, they are more resistant to acid, and their manufacture requires less energy, limiting the environmental footprint [1-3]. Despite the many advantages quoted by numerous authors, significant difficulties still appear in effective use of geopolymer binders due to many reasons and mostly to their behavior overtime. Durability considerations often include and not limited to carboxylation process, possible alkali leaching, significant drying, shrinkage, efflorescence [4-7].

Efflorescence phenomenon ensures the deposit of a white salt on the surface of products. In the case of ordinary Portland cements, efflorescence results from the reaction of $\mathrm{Ca}(\mathrm{OH})_{2}$ with water and $\mathrm{CO}_{2}$. Geopolymer materials with their higher soluble alkali metal concentrations, are much more affected especially when they are exposed to humid air or in contact with water, a white salt which appears is mainly potassium/sodium carbonate heptahydrate $\left(\mathrm{K}_{2} \mathrm{CO}_{2} 7 \mathrm{H}_{2} \mathrm{O} / \mathrm{NaCO}_{2} 7 \mathrm{H}_{2} \mathrm{O}\right)$. The main causes of efflorescence are connected to the physico-chemical characteristics of the stating materials, alkali metal type, formulation and geopolymerization parameters [8-10].

Chantale Njiomou Djangang, djangangc@yahoo.fr | ${ }^{1}$ Department of Inorganic Chemistry, University of Yaounde I, POB 812, Yaounde, Cameroon. ${ }^{2}$ Institute of Research for Ceramics - IRCER, 12 rue Atlantis, 87068 Limoges, France. 
To overcome the efflorescence in geopolymer materials, many attempts including the use of a composite matrix formulation using additives, or the adjustment of the starting materials characteristics have been extensively studied and mainly resulted in limited solutions with however acceptable improvement of properties. Adding silica fume, calcium oxide, calcium sulpho-aluminate, kyanite or $\mathrm{MgO}$ compounds are known to limit the shrinkage and improve the volume stability. Particularly, the use of synthetic $\mathrm{MgO}$ in geopolymer formulation is able to form $\mathrm{Mg}(\mathrm{OH})_{2}$ which control the pore size of pastes and increase the compressive strength $[11,12]$. Using admixtures of Al-rich minerals or calcium compounds as well as the hydrothermal aging can reduce the effect of efflorescence. The use of potassium hydroxide instead of sodium hydroxide is one of the solutions that reduce efflorescence since potassium is more strongly bounded to the aluminosilicate gel network. Besides, $\mathrm{K}$ and $\mathrm{Mg}$ carbonate crystals are less visible than the sodium carbonate crystals $[13,14]$.

Moreover, propensity of efflorescence is also connected to the microstructural characteristics of the product, the type of mixture of raw materials that allows controlling the porosity together with the mechanical and thermomechanical properties can be an attempt to alleviate this undesirable phenomenon which is problematic to the durability of the product. For instance, the monolithic geopolymer refractories are mostly constituted of large aggregates of particles, and also finer powder that together form a complex microstructure. In such structure, large filler refractory grains are linked together by a continuous geopolymer matrix that acts as bonding phase, and the whole system is comparable to the so-called grain and bond microstructure; the latter can display several usefulness in thermal insulation and thermal shock refractories $[15,16]$.

Typically, solid aluminosilicate precursors are metakaolin, blast furnace slags, fly and volcanic ashes. To improve and obtaining a large range of geopolymer properties for various applications, a combination of inputs can be used. The present study aims to determine the effect of solid precursor on the physico-chemical properties, the structural characteristics and the performance in use of geopolymer binders. We used two different and innovative mixtures of precursors in the blend of mineral powders (kaolinite clay, bauxite and talc). Our aim is to optimize the formation of reinforced structural characteristics that are able to improve the properties in use of new geopolymer binders. In addition to this objective, expectation to meet future applications of geopolymer binders in refractory materials, since cordierite and mullite present interesting thermomechanical properties at temperature above $1300^{\circ} \mathrm{C}$. We expect that mullite and cordierite phases will effectively recrystallize in materials during using for firing as refractory $[15,17-19]$. Quantities of each resources were calculated in view to obtain stoichiometry very close to that of both cordierite $\left(\mathrm{Mg}_{2} \mathrm{Al}_{4} \mathrm{Si}_{5} \mathrm{O}_{18}\right)$ and mullite-cordierite $\left(3 \mathrm{Al}_{2} \mathrm{O}_{3} \cdot 2 \mathrm{SiO}_{2}-\mathrm{Mg}_{2} \mathrm{Al}_{4} \mathrm{Si}_{5} \mathrm{O}_{18}\right)$ with the weight ratio of 50:50. To this end, alkaline activation of geopolymers was achieved with potassium alkaline and silicate solutions. In combination with mineral materials, they favor the formation of specific structural characteristics. The structural and microstructural characteristics of the synthetized products were identified by different characterization methods including solid-state nuclear magnetic resonance (NMR) spectroscopy, X-ray diffraction XRD), fourier transform infrared spectroscopy (FTIR) and scanning electron microscopy pectroscopy (SEM). Besides, the leakage of alkali metals on material surface was evaluated.

\section{Materials and methods}

\subsection{Materials}

The starting solid materials used for this work are three natural minerals that are bauxite, kaolin and talc, their chemical and mineralogical characteristics, investigated by inductively coupled plasma Spectroscopy (ICP) and $X$-ray diffraction, respectively, are presented in Table $1[15$, 20-22]. They were grounded in porcelain mortar, dried at $110^{\circ} \mathrm{C}$, and sieved at $75 \mu \mathrm{m}$ before mixed in specific proportions to be close to the theoretical formula of cordierite and mullite-cordierite Table 2 [15, 17]. In a first stage, blends were dry-milled for $4 \mathrm{~h}$. It was followed by a wet milling in porcelain jars for $4 \mathrm{~h}$ with the addition of $60 \mathrm{wt} \%$ of water. Mixtures were dried at $110^{\circ} \mathrm{C}$ and homogenized

Table 1 Chemical and mineralogical compostion of raw minerals

\begin{tabular}{llll}
\hline Oxydes & Bauxite & Kaolin & Talc \\
\hline $\mathrm{SiO}_{2}$ & 0.40 & 39.09 & 59.72 \\
$\mathrm{Al}_{2} \mathrm{O}_{3}$ & 55.6 & 39.44 & 1.39 \\
$\mathrm{Fe}_{2} \mathrm{O}_{3}$ & 1.3 & 0.74 & 5.26 \\
$\mathrm{MnO}$ & 0.01 & 0.00 & 0.05 \\
$\mathrm{MgO}$ & $<0.01$ & 0.13 & 29.09 \\
$\mathrm{CaO}$ & $<0.01$ & $<$ L.D & 0.15 \\
$\mathrm{Na} 2 \mathrm{O}$ & $<0.01$ & $<$ L.D & - \\
$\mathrm{K}_{2} \mathrm{O}$ & 0.03 & 0.30 & - \\
$\mathrm{TiO}_{2}$ & 0.09 & 1.14 & - \\
$\mathrm{P}_{2} \mathrm{O}_{5}$ & - & 0.06 & 0.03 \\
$\mathrm{LOI}^{\mathrm{O}}$ & 39 & 18.48 & 4.69 \\
& Gibbsite & Kaolinite & Talc \\
& Anatase & Gibbsite & Chlorite \\
& Goethite & Illite & Tremolite \\
& - & - & Chromite magnesite \\
\hline
\end{tabular}


Table 2 Formulation of raw mixtures

\begin{tabular}{lll}
\hline Proportion (wt\%) & $\begin{array}{l}\text { Cordierite }(\mathrm{Co}) \\
\left(\mathrm{Mg}_{2} \mathrm{Al}_{4} \mathrm{Si}_{5} \mathrm{O}_{18}\right)\end{array}$ & $\begin{array}{l}\text { Mullite-cordier- } \\
\text { ite }(\mathrm{MuCo}) \\
\left(\mathrm{Al}_{4.5} \mathrm{Si}_{1.5} \mathrm{O}_{9.75}\right)\end{array}$ \\
\hline Kaolin & 53.36 & 77.51 \\
Talc & 42.21 & 21.61 \\
Bauxite & 21.07 & 34.73 \\
Amorphous phase content & 31.00 & 31.16 \\
\hline
\end{tabular}

The fractions of raw materials are on the basic of raw oxides including the water that would not appear in the calcined products. It is why the apparent total is above $100 \mathrm{wt} \%$

by sieving at $75 \mu \mathrm{m}$. Powders were thermally treated at $700^{\circ} \mathrm{C}$ for $4 \mathrm{~h}$ with a ramp of $5^{\circ} \mathrm{C} \mathrm{min}^{-1}$ (Nabertherm electric kiln). The heat treatment leads to the formation of an amorphous structure in the solid precursors, which quantities are $31 \mathrm{wt} \%$ for Co and $31.16 \mathrm{wt} \%$ for MuCo. Precursors were named $\mathrm{Co}$ and MuCo for the cordierite and the mullite-cordierite precursors, respectively.

The alkaline solution was a mixture of equivalent volume of a commercial silicate solution (having a $\mathrm{SiO}_{2} / \mathrm{K}_{2} \mathrm{O}$ molar ratio of 3.01 and a density of $1.38 \mathrm{~g} . \mathrm{cm}^{-3}$ ) and a $8 \mathrm{M}$ potassium hydroxide solution. The latter was obtained by dissolving in distilled water the appropriated weight of a $98.66 \mathrm{wt} \%$ of potassium hydroxide pellets in a volumetric flask, it was allowed for $24 \mathrm{~h}$ cooling at room temperature before using.

\subsection{Methods}

Analyses of fine grains of ground samples $(<63 \mu \mathrm{m})$ included, respectively: Differential thermal and thermogravimetry analyses (DTA/TGA) carried out on the two starting mixtures of three minerals (Netzsch DTA409). For this experiment, $100 \mathrm{mg}$ of sample was placed in platinum crucible, the thermal cycle included a heating rate of $10^{\circ} \mathrm{C}$. $\mathrm{min}^{-1}, 2 \mathrm{~h}$ holding at the peak temperature $\left(1400^{\circ} \mathrm{C}\right)$ and free cooling. The Brunauer-Emmett-Teller (BET) specific surface area of the two precursors was determined by $\mathrm{N}_{2}$ adsorption using a Micrometrics Tristar II 3020 volumetric adsorption/desorption apparatus. Prior to the measurement, the samples were degassed at $200^{\circ} \mathrm{C}$ under vacuum for $4 \mathrm{~h}$. XRD was conducted on a PW3710, Phillips, apparatus operating on a CuKa, Ni-filtered radiation (the wavelength was $1.5406 \AA$ ). The radiation was generated under a current of $40 \mathrm{~mA}$ and a tension of $40 \mathrm{kV}$. Specimens were step-scanned as random powder from $5^{\circ}$ to $70^{\circ} 2 \theta$ steps and integrated at the rate of $2 \mathrm{~s}$ per step. FTIR analyses were with a Bruker Alpha-p, operating in attenuated total reflectance (ATR) mode. Amorphous phase in the two solid precursors was quantified using the method described by Baenla et al. [22|.
Two types of geopolymer binders were obtained and named GeoCo and GeoMuCo for the cordierite and the cordierite-mullite precursors, respectively. The first stage of the process is the mixing of the solid precursors Co or MuCo into the alkaline solution with a ratio of solid $(\mathrm{g})$ to liquid $(\mathrm{mL})$ of 1.7. After homogenization, during $10 \mathrm{~min}$ in a Hobart mixer (M\&O, model N50G), the setting times process of fresh pastes was characterized with a Vicat apparatus according to the EN 196-3 standard. Pastes were casted in cylindrical PVC molds to form test disks (diameter $30 \mathrm{~mm}$; height $60 \mathrm{~mm}$ ) and compacted by vibrations during $10 \mathrm{~min}$ to remove entrapped air bubbles (using an electrical vibrating table $M \& O$, type $202, N_{-} 106$ ). Shaped samples were covered during $24 \mathrm{~h}$ with a thin film of polyethylene to avoid water evaporation during curing at ambient temperature $\left(24 \pm 3^{\circ} \mathrm{C}\right)$. After removing samples from molds, they were continuously covered with a thin film until characterization at different ages of 8, 16, 24 and 32 days. Physical and mechanical properties were linear shrinkage as volumetric rate variation from the measurement of test-disc dimensions with caliper, water absorption using Archimedes method, and compressive strength using $\mathrm{M} \& \mathrm{O}$ press, type $11.50, \mathrm{~N} \_2$, rate of $3 \mathrm{~mm} \mathrm{~min}^{-1}$.

The geopolymerisation mechanisms were discussed from solid-state NMR spectroscopy acquisition with Bruker Advance III $400 \mathrm{MHz}$ spectrometer. ${ }^{29}$ Si magic-angle-spinning (MAS) NMR experiments were acquired at $79.49 \mathrm{MHz}$ in a $7 \mathrm{~mm}$ MAS NMR probe, operating at a spinning speed of $5 \mathrm{kHz}$. A $30^{\circ}$ pulse of $4.3 \mu \mathrm{s}$ length and a recycle delay of $20 \mathrm{~s}$ were used. Chemical shifts were reported relative to TMS. Another set of experiments were obtained with ${ }^{27} \mathrm{Al}$ MAS NMR that were acquired at $104.26 \mathrm{MHz}$ in a $4 \mathrm{~mm}$ MAS NMR probe, operating at a spinning speed of $10 \mathrm{kHz}$. A $30^{\circ}$ pulse of $1 \mu \mathrm{s}$ and a recycle delay of $2 \mathrm{~s}$ were used. Chemical shifts were referenced using a $1 \mathrm{M}$ solution of $\mathrm{Al}\left(\mathrm{NO}_{3}\right)_{3}$. In addition, powders of geopolymers were characterized by XRD, FTIR and SEM analyses (XL40, Philips, The Netherlands). For SEM observation, fractured surfaces were polished and etched in $5 \% \mathrm{HF}-\mathrm{HNO}_{3}$ solution during $30 \mathrm{~s}$. Microanalyses were performed using Energy-dispersive X-ray spectroscopy (EDS) (X_EDS INCA, Oxford Inst.).

The lixiviation on surface of alkali metals was evaluated with 120 days' samples. According to the method described in previous investigations, it proved to be a representative method to quantify the occurrence of efflorescence. Crushed samples $(<2 \mathrm{~mm})$ were soaked in distilled water with a solid/water mass ratio of 1:50 and kept at ambient atmosphere $\left(25 \pm 5^{\circ} \mathrm{C}\right) .20 \mathrm{~mL}$ of the leaching solution was filtered and diluted with distilled water in a ratio of 1:25. The concentrations of $\mathrm{Na}^{+}$(from precursors) and $\mathrm{K}^{+}$(from activation solution) were measured after each $5 \mathrm{~min}$ up to $30 \mathrm{~min}$ and 30 days after by atomic flame photometry (EIEX 6361, Eppendorf), whereas pH was taken 
simultaneously with a digital pHmeter [23]. In addition, test-disc were subjected to partial immersion in distilled water for more than 45 days.

\section{Results}

\subsection{Thermal behavior of starting solid mixtures}

Thermal analyses DTA and TGA curves Figs. $1 a, b$ of the starting mineral materials mixtures are similar for the two types of mixtures. At about $112^{\circ} \mathrm{C}$, an intense endothermic peak with a significant weight loss appeared and is related to the departure of structural water of gibbsite. However, the peak dissymmetry toward the higher temperatures suggest the occurrence of different dehydroxylation processes for boehmite and other alumina hydroxides, which typically occur up to $300{ }^{\circ} \mathrm{C}$ according to Eqs. 1, 2 [24]. An endothermic peak at $574{ }^{\circ} \mathrm{C}$ without weight loss, it is related to the phase transition of quartz alpha to beta. The peak at $660^{\circ} \mathrm{C}$ with a weight loss is related to the dehydroxylation of kaolinite Eq. 3 to metakaolinite and to that of chlorite to form metachlorite.

$$
\underset{\text { Gibbsite }}{1 / 2\left(\mathrm{Al}_{2} \mathrm{O}_{3}\right) \cdot 3 \mathrm{H}_{2} \mathrm{O}} \rightarrow \underset{\text { BlOOH }}{\mathrm{AlOOH}}+2 \mathrm{H}_{2} \mathrm{O}
$$

$2(\mathrm{AlOOH}) \rightarrow \gamma \mathrm{Al}_{2} \mathrm{O}_{3}+2 \mathrm{H}_{2} \mathrm{O}$

boehmite $\quad \gamma$-alumina

At about $822^{\circ} \mathrm{C}$, DTA shown the only exothermic phenomenon due to the metachlorite transformation with the crystallization of forsterite, Eqs. 4, 5 [25];

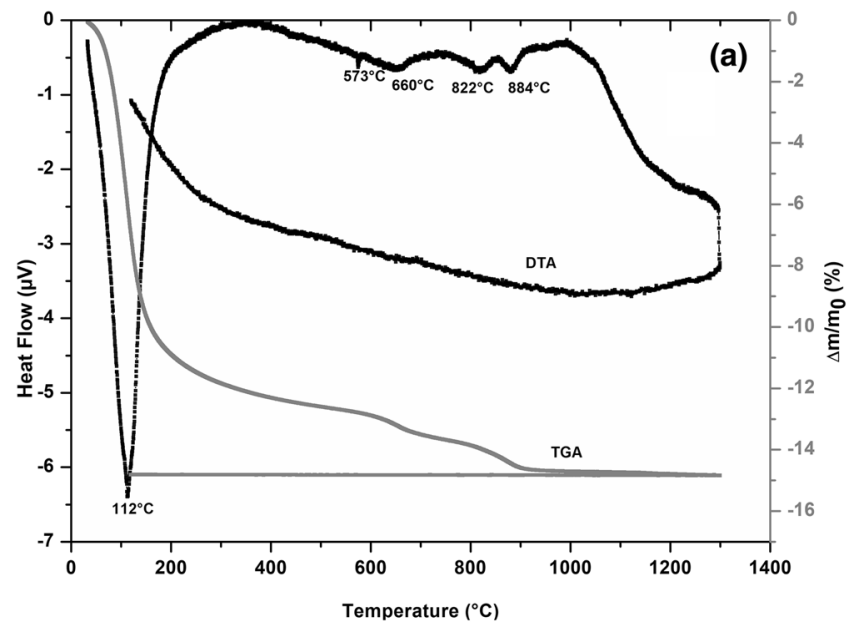

$\mathrm{Si}_{2} \mathrm{O}_{5} \mathrm{Al}_{2}(\mathrm{OH})_{4} \rightarrow 2 \mathrm{SiO}_{2} \cdot \mathrm{Al}_{2} \mathrm{O}_{3}+2 \mathrm{H}_{2} \mathrm{O}$

kaolinite metakaolinite

$\begin{array}{ll}\begin{array}{ll}6 \mathrm{SiO}_{2} \cdot 2 \mathrm{Al}_{2} \mathrm{O}_{3} \cdot 10 \mathrm{MgO} \cdot 8 \mathrm{H}_{2} \mathrm{O} \rightarrow \\ \text { chlorite }\end{array} & \underset{\text { metachlorite }}{6 \mathrm{SiO}_{2} \cdot 2 \mathrm{Al}_{2} \mathrm{O}_{3} \cdot 10 \mathrm{MgO}+8 \mathrm{H}_{2} \mathrm{O}}\end{array}$

$6 \mathrm{SiO}_{2} \cdot 2 \mathrm{Al}_{2} \mathrm{O}_{3} \cdot 10 \mathrm{MgO} \rightarrow 4\left(2 \mathrm{MgO} \cdot \mathrm{SiO}_{2}\right)+2\left(\mathrm{MgO} \cdot \mathrm{Al}_{2} \mathrm{O}_{3}\right)+2 \mathrm{SiO}_{2}$ metachlorite forsterite spinel

The exothermic peak at higher temperature with a weight loss is observed at about $884^{\circ} \mathrm{C}$. It is related to the dehydroxylation of talc, which is transformed into clinoenstatite $\left(\mathrm{MgO}^{\circ} \mathrm{SiO}_{2}\right)$ according to the Eq. 6 [24-26]:

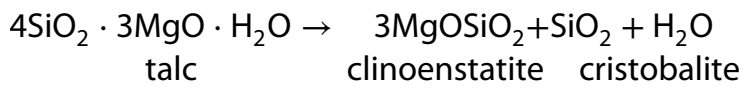

\subsection{Physico-chemical characteristics of solid precursors}

After firing starting solid mixtures at $700^{\circ} \mathrm{C}$, the obtained solid precursors $\mathrm{Co}$ and MuCo displayed specific surface area of $52.29 \mathrm{~m}^{2} \mathrm{~g}^{-1}$ and $41.39 \mathrm{~m}^{2} \mathrm{~g}^{-1}$, respectively. These values are in the range of those obtained elsewhere with different metakaolinite $\left(16-50 \mathrm{~m}^{2} \mathrm{~g}^{-1}\right)$ but higher than those from other common geopolymer precursors:volcanic ashes (16-23 $\left.\mathrm{m}^{2} \mathrm{~g}^{-1}\right)$;-meta-halloysite (16-30 $\left.\mathrm{m}^{2} \mathrm{~g}^{-1}\right)$; - calcined laterite $\left(20-30 \mathrm{~m}^{2} \mathrm{~g}^{-1}\right)$ [27-30]. The significant quantify of an amorphous phase that attain $31 \mathrm{wt} \%$ for Co and $31.16 \mathrm{wt} \%$ for MuCo is favorable in the synthesis process of the geopolymer gel. Figures $2 a, b$ are the XRD patterns of the two mineral precursors. They show a typical halo centered at $30^{\circ} 2 \theta$ that is representative of the amorphous phase of metakaolinite. Peaks of mineral

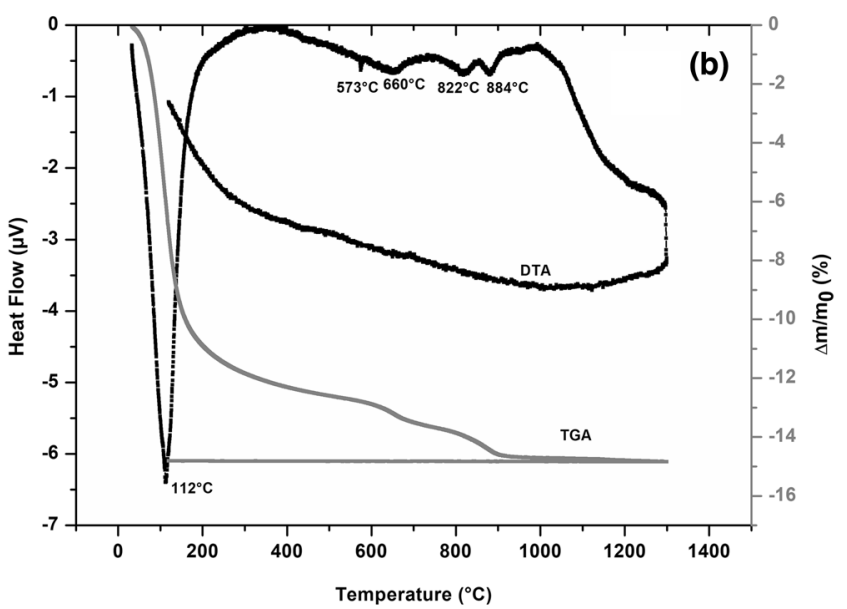

Fig. 1 Thermograms DTA/TGA of a cordierite, $\mathbf{b}$ mullite-cordierite-based mixture of raw minerals 


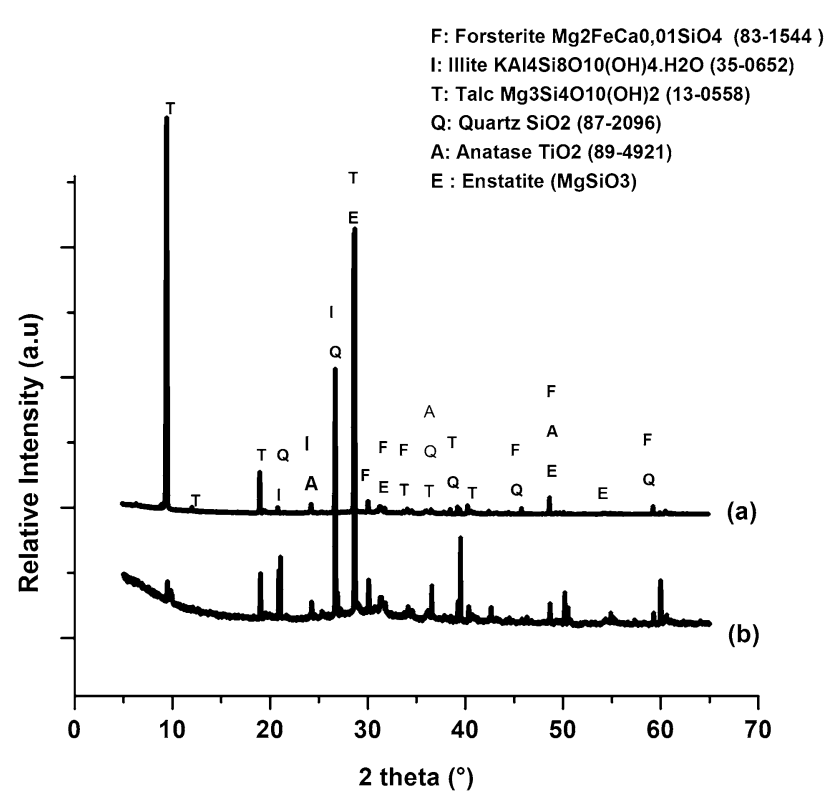

Fig. 2 XRD patterns of solid precursors, a based on Cordierite; $\mathbf{b}$ based on Mullite-Cordierite

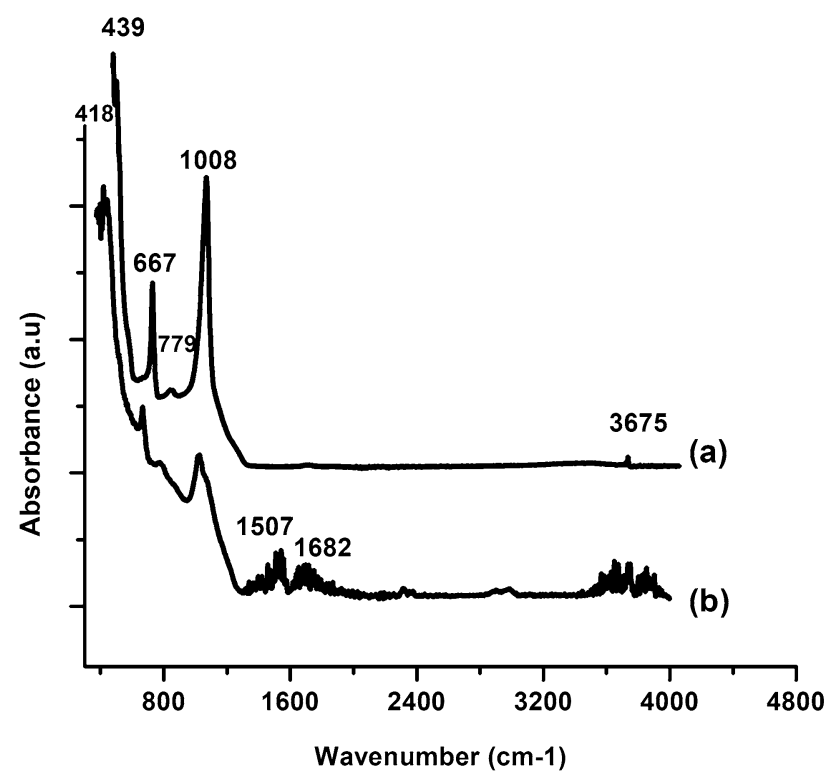

Fig. 3 FTIR spectra of solid precursors a based on Cordierite; $\mathbf{b}$ based on Mullite-Cordierite

phases are from illite, quartz, anatase and talc. Newly formed phases are also identified as forsterite and clinoenstatite. FTIR spectra of precursors in Fig. 3a, b reveal the presence of the aforementioned talc minerals with the $\mathrm{OH}$ stretching vibration band at $3676 \mathrm{~cm}^{-1}$ of $\mathrm{OH}$ surrounded by $3 \mathrm{Mg}\left(\mathrm{Mg}_{3}-\mathrm{OH}\right)$ and that of $\mathrm{OH}$ liberation band observed at $667 \mathrm{~cm}^{-1}$ of $\mathrm{Mg}-\mathrm{OH}$. This band is also characteristic of $\mathrm{Si}-\mathrm{O}$ symmetric vibration. Metakaolinite is evidenced by $\mathrm{Al}-\mathrm{OH} / \mathrm{Al}-\mathrm{O}-\mathrm{Al}$ elongation vibrations where $\mathrm{Al}$ is in $\mathrm{VI}$ - fold coordination at $781.8 \mathrm{~cm}^{-1}$ and the asymmetric elongation vibration of the $\mathrm{Si}-\mathrm{O}-\mathrm{Al}$ or $\mathrm{Si}-\mathrm{O}-\mathrm{Si}$ bonds at $1032 \mathrm{~cm}^{-1}$ $[31,32]$. Another band appeared at $417.8 \mathrm{~cm}^{-1}$ indicating the deformation vibration of the $\mathrm{O}-\mathrm{Si}-\mathrm{O}$ bonds of quartz.

\subsection{Physico-chemical properties of geopolymer binders}

Results of ${ }^{27} \mathrm{Al}$ NMR MAS and ${ }^{29}$ Si NMR MAS are in Fig. $4 a$, b. They characterize the geopolymerization processes of the two types of binders GeoCo and GeoMuCo issued from the activation of solid precursors with alkaline solutions. The ${ }^{27}$ AI NMR MAS spectra recorded for the two geopolymers are similar since they present two broad resonances centered at 58 and $16 \mathrm{ppm}$. The peak at $58 \mathrm{ppm}$ is an identification of a geopolymer. It is from the tetrahedral $\mathrm{Al}-\mathrm{O}$ units and from the sialate units. The peak at $16 \mathrm{ppm}$ arises from residual octahedral $\mathrm{Al}-\mathrm{O}$ units that are from the fraction of unreacted metakaolinite. The ${ }^{29} \mathrm{Si}$ MAS NMR of the two geopolymers also shows similar spectra. A single broad resonance at $-89 \mathrm{ppm}$ is observed. It is representative of geopolymers where $\mathrm{Si}$ are in a Q4(3Al) environment, meaning that they are cross-linked with $\mathrm{SiO}_{4}$ tetrahedra. For GeoMuCo, a small resonance is found at about $-125 \mathrm{ppm}$, which is related to the presence of a small quantity of amorphous silica. [33-36]. Regarding the evidence of an efflorescence phenomenon, the change in appearance and surface color was primarily observed, according to the Munsel color system, the geopolymer test-disc show a dark olive brown color (2.5YR $3 / 6$ ) at earlier age of 1 day after casting, Fig. 5ai-bi. An olive brown color 2.5YR (4/4) appears after 14 days of curing as in Fig. 5aii-bii. Up to 90 days at room temperature and even exposed outside in air with uncontrolled variation of weather, test-disc are still free of efflorescence. The linear shrinkage variation of binders' test-disc as function of time is shown in Fig. 6a, b. It reveals an increase from 1.2 to $2.5 \%$ (8th-24th days of age) and then remain stable up to 32 days. A different effect is observed with compressive strengths Fig. $7 \mathrm{a}$, b. GeoCo products presents a slight increase from 12.7 to $17.7 \mathrm{MPa}$ (8th-32th days of age), and GeoMuCo has higher strength values of 21.6 to $32.9 \mathrm{MPa}$.

XRD patterns of geopolymer binders of the two batches GeoCo and GeoMuCo Fig. 8a, b indicate the presence of talc, enstatite, anatase and quartz in addition to the characteristic halo of the amorphous phase, centered at 2 theta $=28^{\circ}$. FTIR spectrum of Fig. $9 a, b$ for geopolymers reveals that talc is still present after the heat treatment at $700{ }^{\circ} \mathrm{C}$. Vibration bands at $3675 \mathrm{~cm}^{-1}$ are for $\mathrm{OH}$ linked to $\mathrm{Mg}[37,38]$. The bands at 3317,1642 and $1386 \mathrm{~cm}^{-1}$ are attributed to the deformation vibrations of $\mathrm{H}-\mathrm{OH}$ bonds of water molecules bounded to the geopolymer structure Bands at $1003 \mathrm{~cm}^{-1}$ are from the 

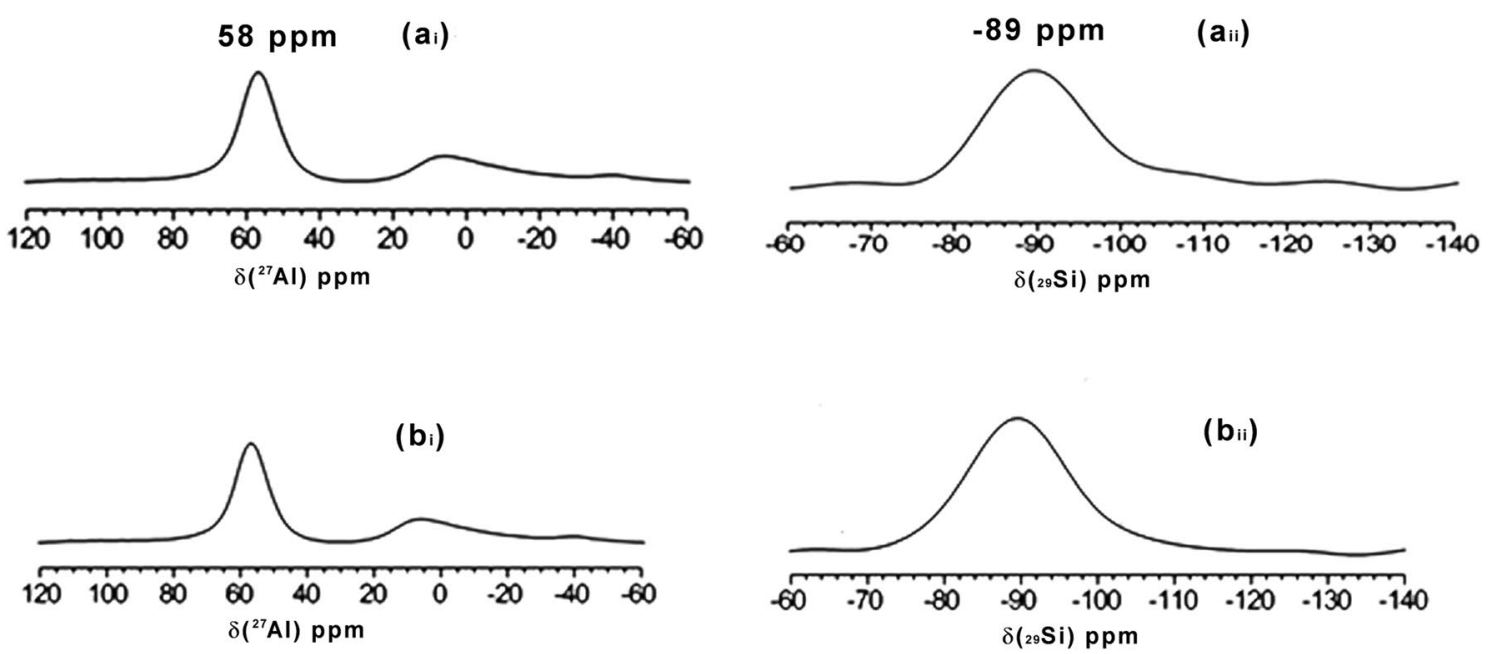

Fig. $4{ }^{27} \mathrm{AI}$ MAS and ${ }^{29}$ Si MAS NMR analyses of geopolymer binders a GeoCo, b GeoMuCo

Fig. 5 Photographs of geopolymer binders test-disc, a GeoCo, b GeoMuCo, (i) 1-day age; (90 -days age)

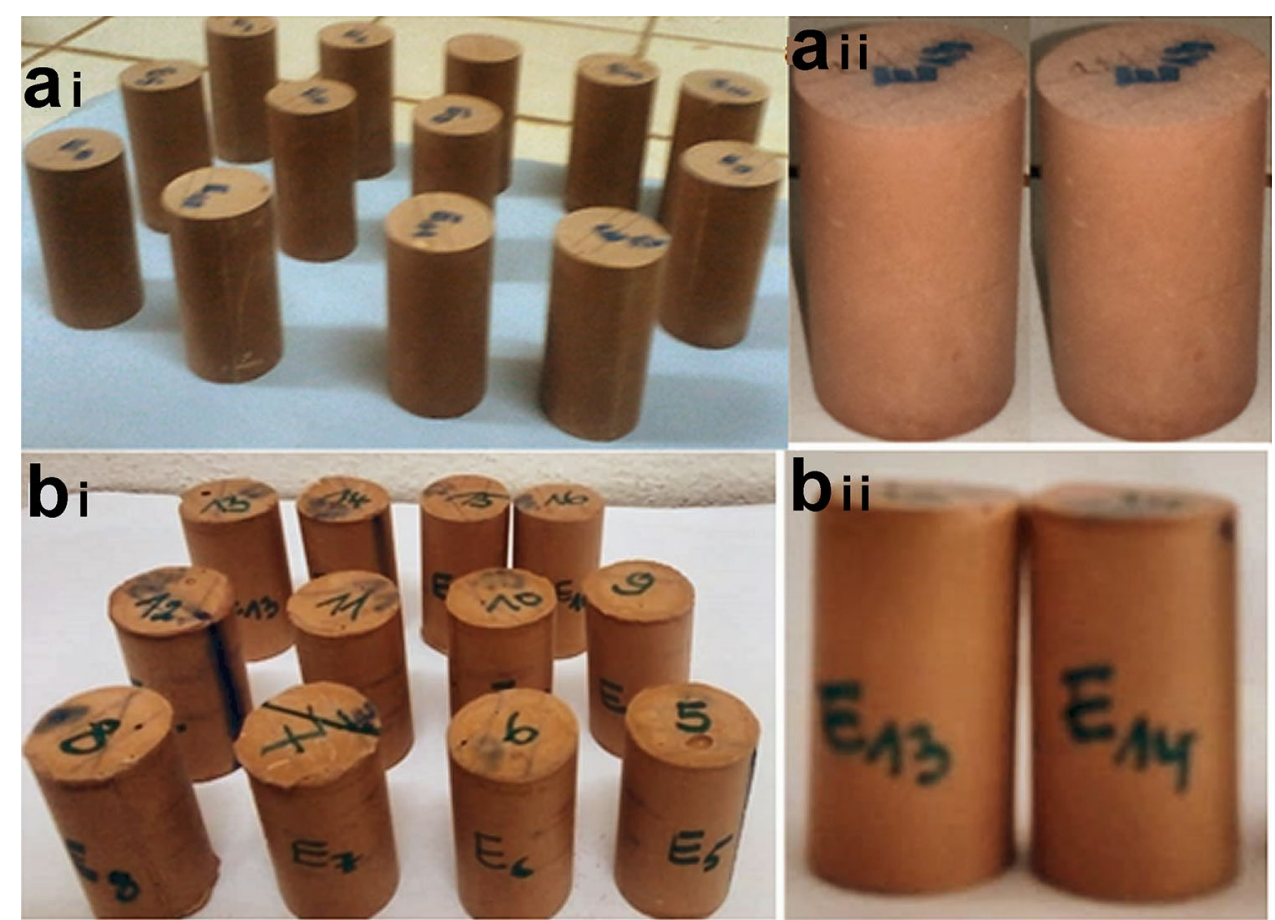

asymmetric stretching vibration of $\mathrm{Si}-\mathrm{O}$ and $\mathrm{Al}-\mathrm{O}$ bonds in structural units $\mathrm{SiO}_{4}$ and $\mathrm{AlO}_{4}$, Al being in IV fold coordination. The band at $668.5 \mathrm{~cm}^{-1}$ is from the symmetrical elongation vibration of $\mathrm{Si}-\mathrm{O}-\mathrm{Si}$ and $\mathrm{Al}-\mathrm{O}$ bonds in geopolymers and that at $421 \mathrm{~cm}^{-1}$ is from $\mathrm{Si}-\mathrm{O}-\mathrm{Si}$ vibrations of internal bonds of quartz [31,38]. Figure $10 a, b$ are SEM and EDS characterizations. Microstructures of the two samples appeared heterogeneous with a variety of contrasts distributed in a regular way; such a morphology is consistent to the minimal surface energy and thus ensures good stability of products. The submersion of geopolymers samples in water triggered the increase of the $\mathrm{pH}$ value from 7.3 to 9.9 during the first $12 \mathrm{~min}$. It stays to this value during 45 days and above. Simultaneously, measurements of leached $\mathrm{Na}$ and $\mathrm{K}$ from pore structure to the immerged Values remain below the detection limit, proving the absence of free alkali and consequently of efflorescence occurrence. 


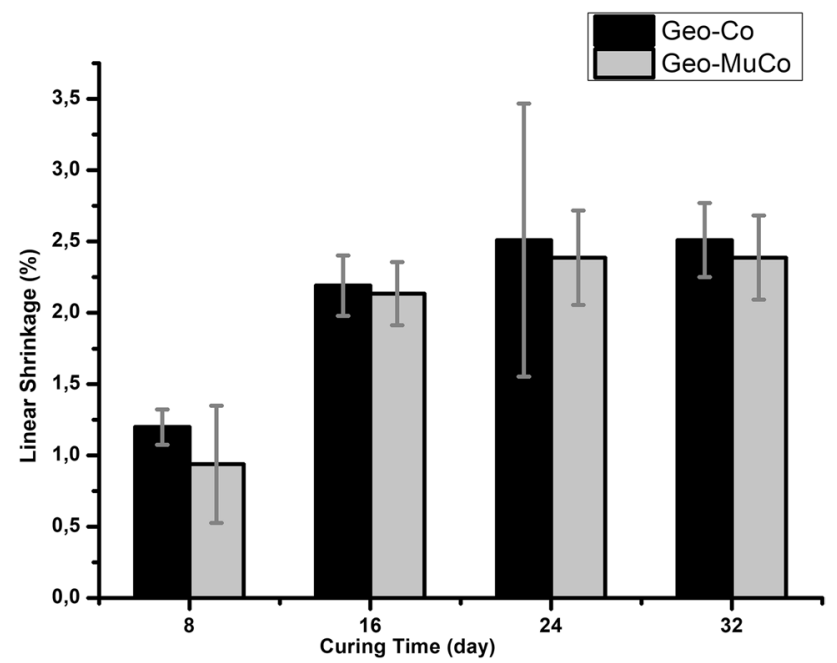

Fig. 6 Variation of linear shrinkage of geopolymer binders test-disc over the age, a GeoCo, b GeoMuCo

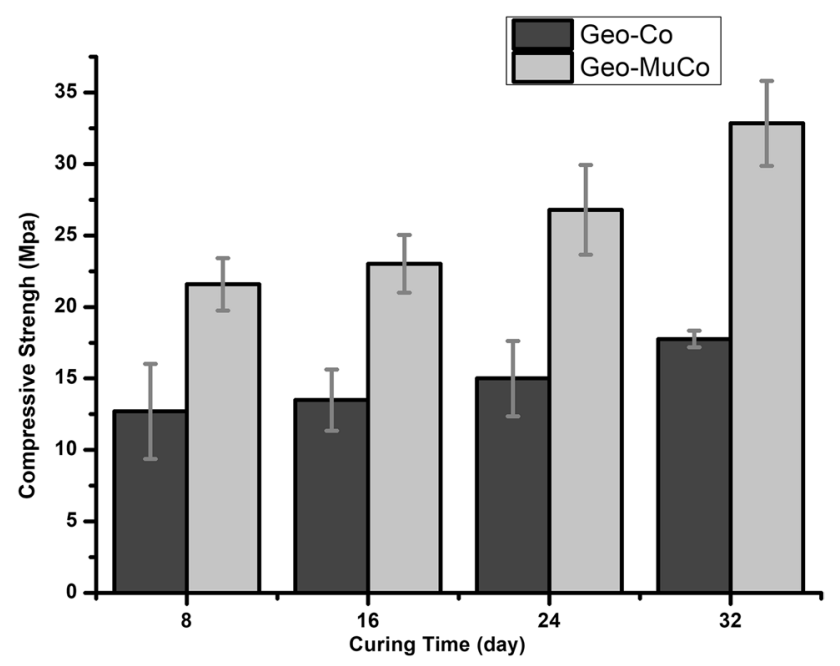

Fig. 7 Variation of compressive strength of geopolymer test-disc over the age, a GeoCo b GeoMuCo

\section{Discussion}

The novelty of this work is based on the specific structural phases contain of solid precursors, in addition to the conventional aluminosilicates $\left(\mathrm{SiO}_{2}\right.$ and $\left.\mathrm{Al}_{2} \mathrm{O}_{3}\right), \mathrm{MgO}$ from talc is included. These mineral precursors showed significant specific surface areas $\left(52.29 \mathrm{~m}^{2} \mathrm{~g}^{-1}\right.$ and 41.39 $\mathrm{m}^{2} \mathrm{~g}^{-1}$ for $\mathrm{Co}$ and $\mathrm{MuCo}$, respectively). The specific surface area is the surface of the particles including that of the accessible open pores. It is related to not only the size of the elementary particles, but also to the type of phases. It is also related to both the surface reactivity

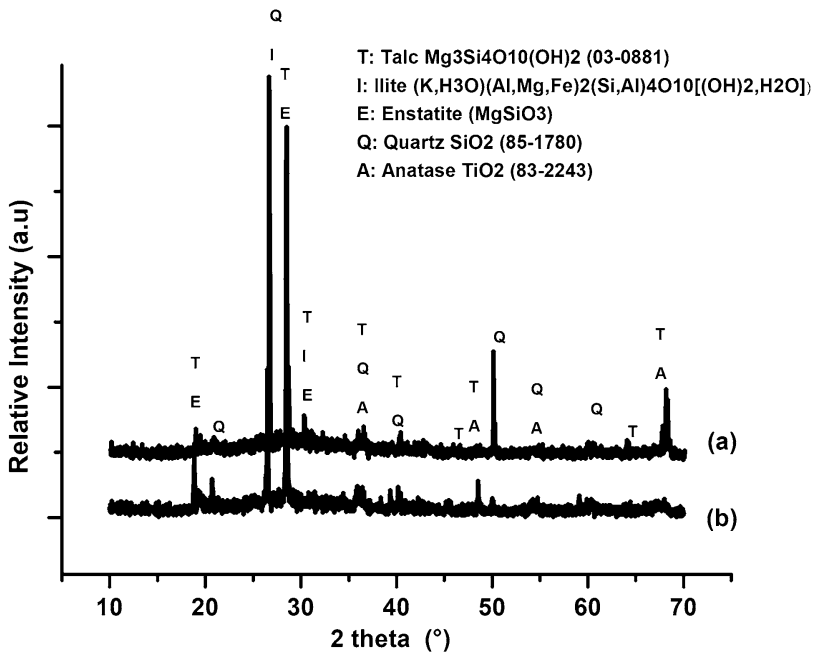

Fig. 8 XRD patterns of geopolymer binders a GeoCo, $\mathbf{b}$ GeoMuCo

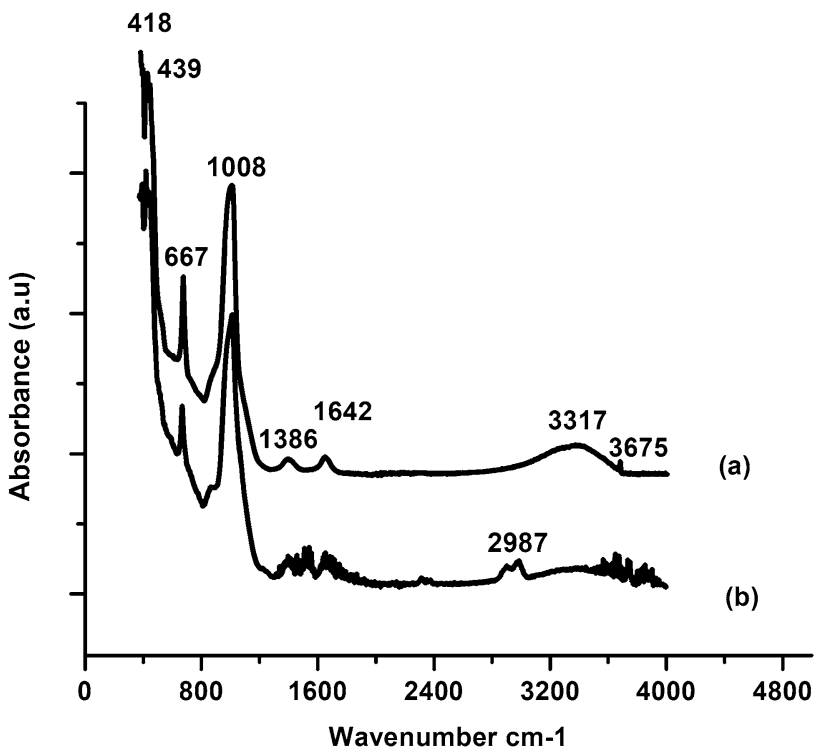

Fig. 9 FTIR spectrum of geopolymer binders a GeoCo, b GeoMuCo

and amorphous phase content of the precursors in the presence of the alkaline solution [22,39]. MuCo is expected to have higher SSA since the thermal analyses reveal that metakaolinite is the major phase (Table 2). Regarding the amorphous phase content, the two precursors contain quasi similar amounts, and this phase can be supposed to favor the reactivity, that lead to the formation of a geopolymer gel. However, SSA of Co precursor significantly exceeds that of MuCo precursor, evidencing the role of talc. It is correlated to XRD patterns Fig. 2a, $b$ of the two precursors where talc and enstatite (a high temperature form of talc) are evidenced, mostly in the Co precursor. XRD also reveal the 


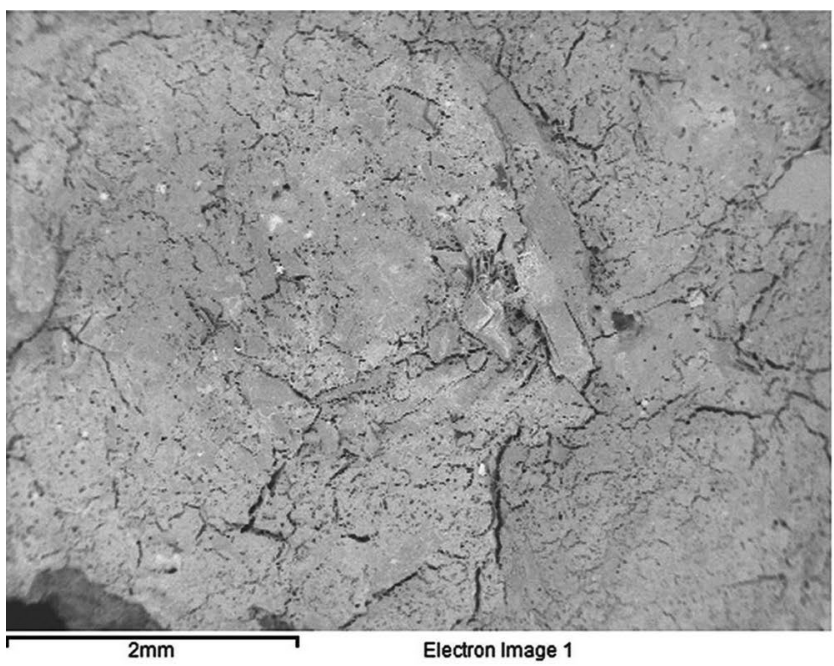

(a)
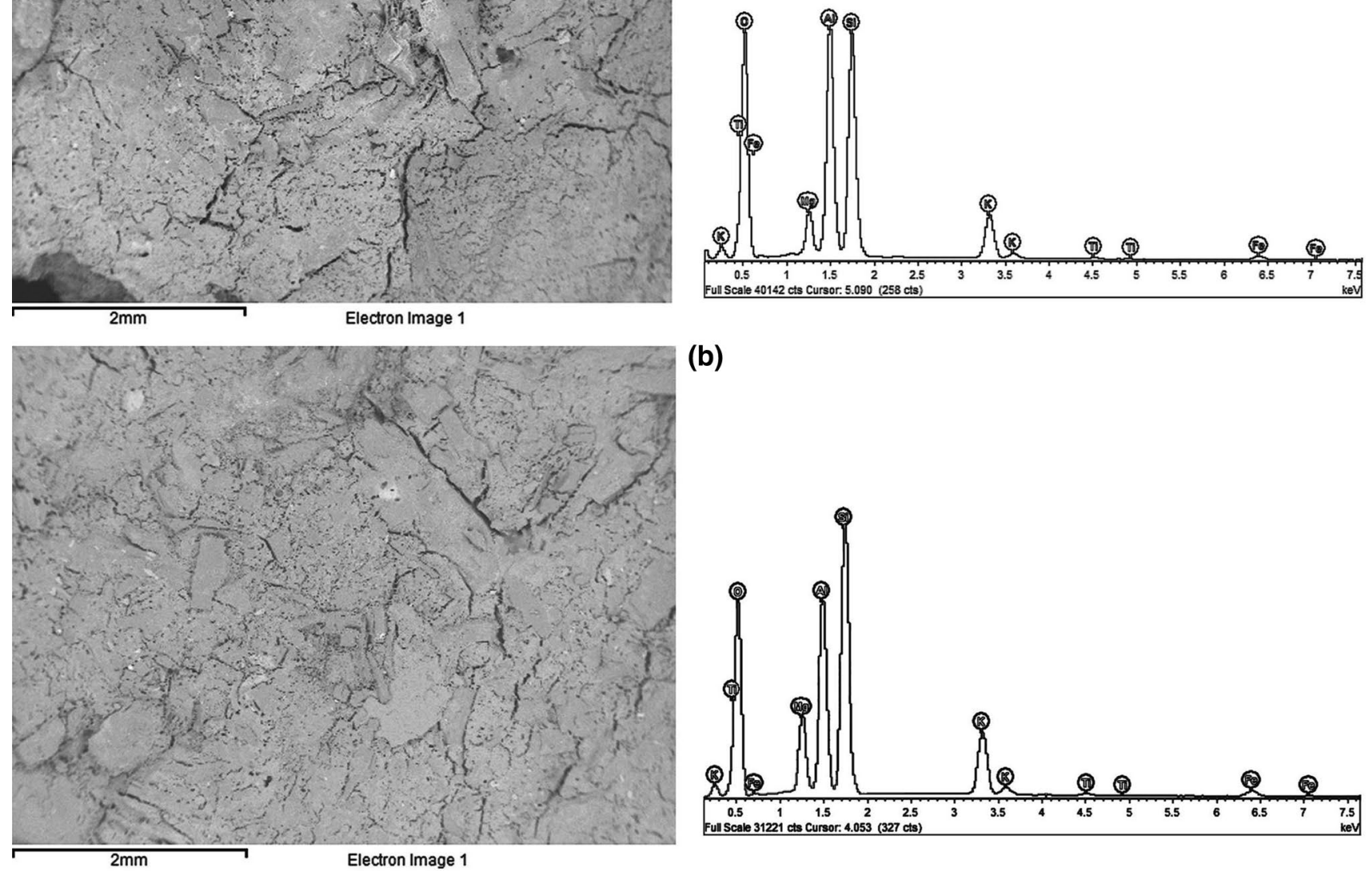

(b)

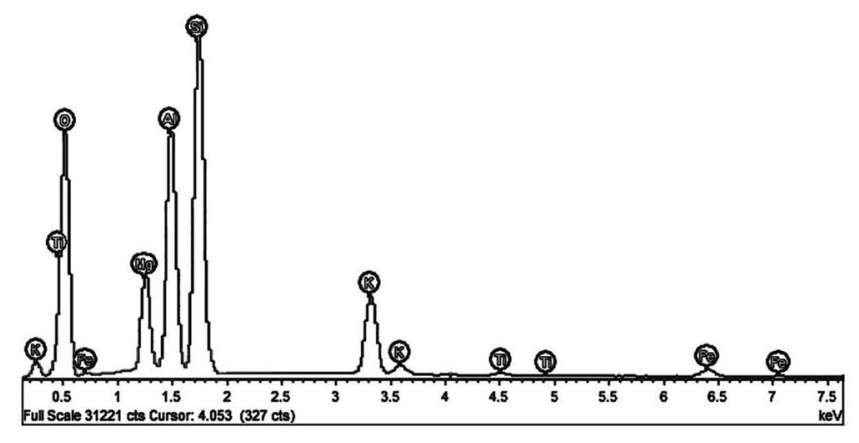

Fig. 10 SEM micrographs/EDS of geopolymer binders a GeoCo; b GeoMuCo

existence of an amorphous phase with phyllosilicates, quartz, anatase, forsterite and clinoenstatite. Mostly the amorphous phase and the phyllosilicates have an effective contribution to SSA. Correspondingly, Fig. 2 reveals higher amounts of these phases in Co precursor than with CoMu precursor. FTIR spectra Fig. 3a, b for Co and MuCo precursors also indicate differences in phase quantities. For $\mathrm{Co}$, bands at $3676 \mathrm{~cm}^{-1}$ of $\mathrm{OH}$ surrounded by $3 \mathrm{Mg}\left(\mathrm{Mg}_{3}-\mathrm{OH}\right)$ and $\mathrm{Mg}-\mathrm{OH}$ at $667 \mathrm{~cm}^{-1}$ are more accentuated. In CoMu, bands are vanished and replaced by a distribution of bands in two areas: $3900-3600 \mathrm{~cm}^{-1}$ and $1650-1300 \mathrm{~cm}^{-1}$. Besides, the band at $667 \mathrm{~cm}^{-1}$ of $\mathrm{Mg}-\mathrm{OH}$ is reduced [31, 32]. It is a further indication of the reduction of structural order of phyllosilicates, with a lesser contribution to SSA.

${ }^{27} \mathrm{AI}$ MAS and ${ }^{29}$ Si MAS NMR analyses Fig. 4 a-b evidence the presence of tetrahedral Al-O units of the sialate units and residual octahedral $\mathrm{Al}-\mathrm{O}$ units, coming from metakaolinite. Results also evidence the formation of a geopolymer network with cross-linked $\mathrm{SiO}_{4}$ tetrahedra (resonance at -89 ppm in Fig. 4b). Some authors have obtained similar resonance but in the range of -82 to $92 \mathrm{ppm}$ depending on the $\mathrm{Si} / \mathrm{Al}$ molar ratio [33-36]. The value of 1.8 used in our study is in the range of that used in other studies. In the case of GeoMuCo, a resonance is found at $-125 \mathrm{ppm}$, which could be associated with the presence of amorphous silica in SiQ4(xAl) configuration, where $x=0.1$. They are residual units that are not into the geopolymer network. From the 29Si MAS NMR of binders, two types of silicates compounds are identified (free $\mathrm{SiO}_{4}$ and cross-linked $\mathrm{SiO}_{4}$ ). Similarly, ${ }^{27} \mathrm{Al}$ MAS NMR highlighted the presence of $\mathrm{AlO}_{4}$ and residual $\mathrm{AlO}_{6}$ structural units. The strong alkaline medium favors the formation of Al-substituted silicate layers where Al sites become fourcoordinated Al sites. The polycondensation, is issued from a three-dimensional network with $\mathrm{Si}-\mathrm{O}-\mathrm{Al}$ as a backbone 
with $\mathrm{Al}(\mathrm{IV})$ in tetrahedral sites and into the silica polymer network. $\mathrm{K}^{+}$ions contribute to the electroneutrality. The MAS NMR signals are strongly affected by a quadrupole broadening as well as a further broadening due to the interactions with some unreacted oxides namely the iron and titanium impurities from starting materials. Particularly, the magnesium group minerals as talc are scarcely involved in geopolymer gel formation. Besides the setting time increases strongly to attains $197 \mathrm{~min}$ for GeoCo and $105 \mathrm{~min}$ for GeoMuCo. The setting time, which is the time from mixing liquid and solid precursors and the solidification, is characterized by the increase of consistency that is the polycondensation phenomenon. The setting time depends in many parameters as the concentration and the $\mathrm{SiO}_{2} / \mathrm{Na}_{2} \mathrm{O}$ or $\mathrm{K}_{2} \mathrm{O}$ molar ratio of liquid precursor, and the chemical and structural compositions of solid precursors. With metakaolin as solid precursor, the low molar ratio $\mathrm{SiO}_{2} / \mathrm{Al}_{2} \mathrm{O}_{3}$ induces a low setting time (45-100 min).. Accordingly, GeoCo binder from a mixture with a higher metakaolinite and talc contents exhibits a longer setting time, although the higher specific surface area of the mineral precursor $\left(52.29 \mathrm{~m}^{2} \mathrm{~g}^{-1}\right)$ in comparison to that of GeoMuCo $\left(41.39 \mathrm{~m}^{2} \mathrm{~g}^{-1}\right)$. Although the specific surface area is an indication on the chemical reactivity, the presence of $\mathrm{Mg}$ bearing phases as talc has a limiting effect in reactivity during setting [40]. XRD patterns of geopolymer binders GeoCo and GeoMuCo Fig. 8a, b evidence the presence of talc and quartz in addition to the characteristic amorphous halo centered at $28^{\circ} 2 \theta$. FTIR spectrum Fig. 9a, $b$ is also an indication on the presence of talc. The presence of different phase is also observed by microstructural and microanalyses characterizations. Microstructural morphology and EDS analyse are in Fig. 10a, b heterogeneous microstructure is evidenced although different phases are distributed in the volume. The EDS analyses show the main constituent elements of the geopolymer that are derived from the starting minerals. Differences are found between binders Geo-Co and Geo-MuCo since the Al to $\mathrm{Si}$ ratio is higher with MuCo than for Co precursor. Besides, $\mathrm{Mg}$ content is higher for Co precursor. It pointed out the important role of mineral precursors in the geopolymer characteristics after setting. According to the Munsel color system, geopolymer test-disc showed a red coloration that is not strongly changed with the setting time. The absence of efflorescence on surfaces is an indication on the reduction on mobile species with $\mathrm{K}^{+}$or $\mathrm{Na}^{+}$ions for carbonate heptahydrate $\left(\mathrm{K}(\mathrm{Na})_{2} \mathrm{CO}_{3} \cdot 7 \mathrm{H}_{2} \mathrm{O}\right)$. $\mathrm{K}^{+}$ions are from the activation solutions and has a role in the charge balance into the geopolymer framework. It proves that the dissolution process does not involve the diffusion of alkaline species from the volume or the internal pores. In that way, they are not exposed to both atmospheric carbon dioxide and air humidity $[41,42]$.
. The presence of $\mathrm{MgO}$ specie appears as a key point that favor an increased physico-chemical stability of products. The talc role is further evidenced with the linear shrinkage of binders Fig. $6 a$, $b$ It exhibits an increase from 1.2 to $2.5 \%$ (8th-24th days of age) and then remain stable up to 32 days. For longer times, GeoCo present very small length variations. It is related to the initial talc content that is higher than that of GeoMuCo, which shrinkage increases from 1 to $2.9 \%$ during the same period. A different effect is observed with compressive strengths Fig. $7 a$, $b$ that present a slight increase from 12.7 to $17.7 \mathrm{MPa}$ (8th-32th days of age) for GeoCo and from 21.6 to 32.9 MPa for GeoMuCo. It proves that talc do not induce very high value of mechanical strength since the highest value of this study $(32.9 \mathrm{MPa})$ is a little less than those of geopolymers with conventional solid precursor as metakaolin and volcanic ashes [40]. This is because, the quantity of geopolymer gel formed was low accordingly to the part of solid precursor which effectively took part to the reaction against the unreactive part constituted by talc.

The immersion of geopolymers in water result in the increase of $\mathrm{pH}$ from 7.3 to 9.9 during the first $12 \mathrm{~min}$. It remains constant over the following 28 days and more. The kinetic of $\mathrm{pH}$ increase is lower for GeoCo in comparison to that of GeoMuCo. However, the leaching process is not accompanied by efflorescence. Surfaces of samples remain unchanged, with no trace of peeling or color change. The chemical analyses of alkali metals $\mathrm{Na}^{+}$and $\mathrm{K}^{+}$in the leaching solution indicated values below the limit of detection. It proves the absence of free alkali and consequently of efflorescence since this phenomenon results from the diffusion from the bulk material to surface of alkali metals. In a different situation, free alkaline cations would react with atmospheric carbon dioxide, forming sodium and/or potassium carbonate under the form of a white deposit on surface. In previous investigations, the leaching behavior of $\mathrm{Na}^{+}$and $\mathrm{K}^{+}$, and group 1 elements was observed from geopolymers in an aqueous liquid. In general, diffusion kinetic of ions is independent from $\mathrm{pH}$. In our study, $\mathrm{pH}$ was measured at a quasi-constant value of 9.9. It is consistent to the typical alkaline character of the geopolymers, not really underlining the leaching of alkali metals $\mathrm{Na}^{+}$ and $\mathrm{K}^{+}$in solution, meaning that a very small quantity is leached from our material, especially during the early stage of immersion $[28,39,42]$. In the case of a $\mathrm{pH}$ variation up to 10.3 value and above, the predominant reaction would be with surface $\mathrm{CO}_{3}{ }^{2-}$ ions to form potassium or sodium carbonate. Below this $\mathrm{pH}$ value, the equilibrium reaction on surface is changed and most probably, bicarbonate or hydroxycarbonate are formed [43]. Regarding the source of leached elements, they are originated from both solid and liquid precursors and are part of initial content, which are not involved in geopolymer gel network. 
Concerning the liquid precursor, the blend of potassium hydroxide and potassium silicate is used in this work, and mostly the lixiviation of $\mathrm{K}^{+}$was expected. Finally, the solid precursor is not only composed of metakaolin with active silica and alumina structural units but with talc providing magnesium species. Consequently, the role of magnesium oxide is evidenced since it has changed the typical behavior of aluminosilicate precursors to exhibit efflorescence on geopolymers.

\section{Conclusion}

Efflorescence is an unsuitable phenomenon that results from the reaction between atmospheric carbon dioxide and leached alkali metals that are not involved in the geopolymer gel network. In this work, geopolymer binders that did not undergo any efflorescence were successfully obtained from alternative solid precursors. The solid precursors used are from usual aluminosilicate sources but with talc addition. Talc provides magnesium species, which are also involved in the formation of the geopolymer gel network. With well-controlled solid precursors, a potassium compound was chosen for the activator solution since its behavior in the gel phase formation differs from that of sodium compound. Characterization methods by spectroscopy (XRD, FTIR, NMR) results in effective identification of phases in the geopolymer matrix that are mostly alumino-silicate compounds with magnesium. The main behavior of these phases is the relatively stable structural characteristics, meaning a reduced leakage of elementary species under atmospheric changes. It leads to a reduced diffusion process of species towards the external surface, which limit drastically the efflorescence phenomena. Besides, potassium compounds induce a limited value of $\mathrm{pH}$ of 9.9 in the surroundings that reduce considerably the leaching of alkali metals in water. As consequence, there is no carbonate salts formation on surface.

Acknowledgements A part of research was carried out at the University of Pavia, Italy, through the scholarships award of the University CICOPS. Other experiments were performed at the Institute of Research for Ceramics - IRCER, France through a long-time partnership with to the University of Yaounde I, Cameroon. Acknowledgments are for the financial support of TWAS institution (The World Academy of Science) under the grant RG / 19-206 RG/CHE/AF/AC_G $/ 4500411470$

Author contributions Chantale Njiomou Djangang: conceptualization, methodology, writing and editing original draft Jean Aime Mbey: original draft-reviewing Cyprien Joel Ekani: investigation and data collection-original draft preparation Severin Tabou Tiam: investigation and data collection- original draft preparation Philippe Blanchart: reviewing Daniel Njopwouo: supervision.
Funding There was no special funding for this research, it has however benefited the facilities available with the assistance of some projects named in the acknowledgment.

\section{Compliance with ethical standards}

Conflicts of interest The authors declare that they have no conflict of interest.

Data availability and materials The datasets analyzed during the current study are available from the corresponding author on reasonable request.

\section{References}

1. Provis JL (2014) Geopolymers and other alkali activated materials: why, how, and what? Mater Struct 47(1-2):11-25

2. Amran MHY, Alyousef R, Alabduljabbar H, El-Zeadani M (2019) Clean production and properties of geopolymer concrete. Rev J Clean Prod 251:119679

3. Albitar M, Ali M, Visintin P, Drechsler KM (2017) Durability evaluation of geopolymer and conventional concretes. Constr Build Mater 136:374-385

4. Sara BJ, Kumutha R, Vijai K (2017) A review on durability studies of geopolymer concrete and mortar under aggressive environment. SSRG Int J Civil Eng 4(5):32-35

5. Zhang Z, Wang H, Provis JL, Reid A (2013) Efflorescence: a critical challenge for geopolymer applications? In: 2013 Concrete institute of australia's biennial national conference Concrete Institute of Australia. p. 1-10

6. Awoyera P, Adesina A (2019) A critical review on application of alkali activated slag as a suitable composite blinder. Case Stud Constr Mater 11:1-13

7. Longhi MA, Zhang Z, Rodríguez ED, Kirchheim AP, Wang H (2019) Efflorescence of Alkali-activat cements (geopolymers) and the impacts on material structures: a critical analysis. Front Mater 6:89

8. Longhi MA, Rodríguez ED, Walkley B, Zhang Z, Kirchheim AP (2020) Metakaolin-based geopolymers: Relation between formulation, physicochemical properties and efflorescence formation. Compos B Eng 182:107671

9. Zhang Z, Provis J, Ma X, Reil A, Wang H (2018) Efflorescence and subflorescence induced microstructural and mechanical evolution in fly ash-based geopolymers. Cement Concr Compos 92:165-177

10. Skvara F, Kopecky L, Myskova L, Smilauer V, Alberovska L, Vinsova $L$ (2008) Aluminosilicates polymers- Influence of elevated temperature, efflorescence. Ceramics Silikaty 53(4):276-282

11. Kani EN, Allahverdi A, Provis JL (2012) Efflorescence control in geopolymer binders based on natural pozzolan. Cement Concr Compos 34(1):25-33

12. Allahverdi A, Kani EN, Hossain KMA, Lachemi M (2015) Methods to control efflorescence in alkali-activated cement-based materials. Handbook of alkali-activated cements, mortars and concretes. Woodhead Publishing, Cambridge, pp 463-483

13. Li Z, Zhang W, Wang R, Chen F, Jia X, Cong P (2019) Effects of reactive $\mathrm{MgO}$ on the reaction process of geopolymer. Materials 12(3):526

14. Schuler MP (2015) Prevention and elimination of masonry efflorescence. J Cement Appl 6:73-78

15. Djangang NC, Cristina TA, Cattaneo $S$, Piercarlo M, Kamseu E, Cristina L (2015) Cold-setting refractory composites from 
cordierite and mullite cordierite design with geopolymer paste as binder: thermal behavior and phase evolution. Mater Chem Phys 154:66-77

16. Nurfadilla MD, Fardina R (2016) The potential of geopolymer as high quality refractory. Mater Sci Forum 841:21-25

17. Kamseu E, Djangang NC, Veronesi P, Fernanda A, Melo UC, Sglavo VM, Leonelli C (2015) Transformation of the geopolymer gels to crystalline bonds in cold-setting refractory concretes: pore evolution, mechanical strength and microstructure. Mater Des 88(25):336-344

18. Njoya D, Elimbi A, Fouejio D, Hajjaji M (2016) Effects of two mixtures of kaolin-talc-bauxite and firing temperatures on the characteristics of cordierite-based ceramics. J Build Eng 8:99-106

19. Nergis BDD, Mustafa Al Bakri BAMM, Sandu VA, Vizureanu P (2020) XRD and TG-DTA Study of new alkali activated materials based on fly ash with sand and glass powder. Materials 13:343

20. Nkoumbou C, Villieras F, Njopwouo D, Ngoune CY, Barres O, Pelletier M, Razafitianamaharavo A, Yvon J (2008) Physicochemical properties of talc ore from three deposits of Lamal Pougue area (Yaounde Pan-African Belt, Cameroon), in relation to industrial uses. Appl Clay Sci 41:113-132

21. Tchamba AB, Mbessa M, Sontia MJV, Yang L, Tankeu NS, Nkeng EG, Njopwouo D, Bier T (2020) Mechanical and microstructural properties of cameroonian bauxite ceramics for ballistic applications. Int J Appl Ceram Technol 17:949-962

22. Baenla J, Mbah BBJ, Djon BI, Elimbi A (2019) Partial replacement of low reactive volcanic ash by cassava peel ash in the synthesis of volcanic ash based geopolymer. Constr Build Mater 227:116689

23. Sun Z, Vollpracht A, van der Sloot HA (2019) pH dependent leaching characterization of major and trace elements from fly ash and metakaolin geopolymers. Cem Concr Res 125:105889

24. Jouenne CA (2001) Traité de céramiques et matériaux minéraux. Septima Paris

25. Sorgho B, Zerbo L, Seynou M, Traore K, Ouedraogo R, Gomina M, Blanchart $P$ (2012) Caractérisation physico-chimique d'un talc naturel de Garango (Burkina Faso). Science et Technique 4(1 \& 2):49-59

26. Liu $X$, Hu Y (2014) Investigation of the thermal decomposition of talc. Clays Clay Miner 62(2):137-144

27. Kirschner AV, Harmuth H (2004) Investigation of geopolymer binders with respect to their application for building materials. Ceram-Silik 48(3):117-120

28. Pouhet R, Cyr M (2015) Alkali-silica reaction in metakaolin-based geoplymer motar. Mater Struct 48(3):571-586

29. Tchakouté HK, Elimbi A, Yanne E, Djangang CN (2013) Utilization of volcanic ashes for the production of geopolymers cured at ambient temperature. Cement Concr Compos 38:73-81
30. Poudeu RC, Ekani CJ, Djangang CN, Blanchart P (2019) Role of heat-treated laterite on the strengthening of geopolymer designed with laterite as solid precursor. Annales de Chimie Science des Matériaux 43(6):359-367

31. Goodman BA (1994) Clay mineralogy: spectroscopic and chemical determinative methods. Chapman \& Hall, London

32. Ngally Sabouang CJ, Mbey JA, Hatert F, Njopwouo D (2015) Talcbased cementitious products: effect of talc calcination. J Asian Ceram Soc 3(3):360-367

33. Rocha J, Klinowski J (1990) Etudes par RMN du 29 Si et 27 Al par rotation à angle magique de la transformation thermique de la kaolinite. Physique et Chimie des Minéraux 17(2):179-186

34. Singh PS, Bastow T, Trigg M (2005) Structural studies of geopolymers by $29 \mathrm{Si}$ and 27 AI MAS-NMR. J Mater Sci 40(15):3951-3961

35. Brus J, Abbrent S, Kobera L, Urbanova M, Cuba P (2016) Advances in 27AI MAS NMR studies of geopolymers. Annu Rep NMR Spectrosc 88:79-147

36. Bhardwaj P, Gupta R, Mishra D, Amritphale SS (2019) Quadri functionality variation of aluminosilicate silicon nucleus on solid state geopolymerisation observed by 29 Si magic angle spinning nuclear magnetic resonance studies. Silicon 11(4):2127-2133

37. Lee WKW, Deventer JSL (2003) Use of infrared spectroscopy to study geopolymerization of heterogeneous amorphous aluminosilicates. Langmuir 19(21):8726-8734

38. Sufian MZ, Khan SA, Ulla H, Siyal AA (2016) A short review of the infra-red spectroscopic studies of geopolymers. Adv Mater 1133:231-235

39. Nergis DDB, Abdullah MMAB,Vizureanu P (2017) The effect of fly ash/alkaline activator ratio in class $\mathrm{f}$ fly ash based geopolymers. Euro J Mater Sci Eng 2(4):111-118

40. Kenneth JD, MacKenzie SB, John V, Hanna SME (2013) Magnesium analogues of aluminosilicate inorganic polymers (geopolymers) from magnesium minerals. J Mater Sci 48:1787-1793

41. Kuenzel C, Ranjbar N (2016) Dissolution mechanism of fly ash to quantify the reactive aluminosilicates in geopolymerisation. Resour Conserv Recycl 150:104421

42. Ranjbar N, Kuenzel C, Spangenberg J, Mehdi Mehrali M (2020) Hardening evolution of geopolymers from setting to equilibrium: a review. Cement Concr Compos 114:103729

43. Kosson DS, Hans A, Sloot VD (2014) pH-dependent leaching of constituents of potential concern from concrete materials containing coal combustion fly ash. Chemosphere 103:140-147

Publisher's Note Springer Nature remains neutral with regard to jurisdictional claims in published maps and institutional affiliations. 